\title{
Design, construction and evaluation of a Fresnel Linear Concentrator for Oil Heating
}

\author{
Diseño, construcción y evaluación de un concentrador lineal de Fresnel para \\ calentamiento de aceite
}

\author{
N. De-la-Hoz-Muñoz iD ; H. Julio-González iD ; C. A. Pedraza-Yepes iD ; O. F. Higuera-Cobos iD ; J. D. \\ Hernández-Vásquez iD
}

\begin{abstract}
The goal of this work is to describes the design and development of a fresnel linear concentrator that be able to concentrate sun radiations towards a receiver tube with a concentration ratio of $\mathbf{1 1 . 5 4}$. The methodology applied allowed to analysis the spacing, the inclinations and the adequate widths of the mirrors that would be more convenient to obtain the highest solar concentration factor and the minimum optical and thermal losses. The design of the solar concentration collector consisted of a $3.5 \mathrm{~m} \times 3.0 \mathrm{~m} \times 2.65 \mathrm{~m}$ system with 15 mirrors, each one measuring $0.12 \mathrm{~m}$ wide, and a receiving center height of $2.0 \mathrm{~m}$. The experimental results confirmed that the maximum process temperature of $140{ }^{\circ} \mathrm{C}$ was achieved. In addition, a thermal oil storing was $995 \mathrm{~kJ}$-h available in a 6-hour (since 9:00h until 15:00h). The performance tests of the system were performed in the city of Barranquilla, with local environmental conditions. The experimental tests of the prototype finally allowed to validate the design proposed in this present work.
\end{abstract}

Index Terms - Fresnel, Low enthalpy, Optical analysis, Solar linear collector.

Resumen - El objetivo de este trabajo es describir el diseño y desarrollo de un concentrador lineal de Fresnel que pueda concentrar las radiaciones solares hacia un tubo receptor con una relación de concentración de 11,54. La metodología aplicada permitió analizar el espaciado, las inclinaciones y los anchos adecuados de los espejos más convenientes para obtener el mayor factor de concentración solar y las pérdidas ópticas y térmicas mínimas. El diseño del colector de concentración solar consistió en un sistema de $3.5 \mathrm{~m} \times 3.0 \mathrm{~m} \times 2.65 \mathrm{~m}$ con 15 espejos, cada uno de $0.12 \mathrm{~m}$ de ancho, y una altura central de recepción de $2.0 \mathrm{~m}$. Los resultados experimentales confirmaron que se alcanzó la temperatura máxima del proceso $140{ }^{\circ} \mathrm{C}$. Además, el almacenamiento de aceite térmico fue de $995 \mathrm{~kJ}$-h disponibles en 6 horas (desde las 9: 00h hasta las 15: 00h). Las pruebas de rendimiento del sistema se realizaron en la ciudad de

This manuscript was sent on January 25, 2019 and accepted on June 26, 2019.

N. de-la-Hoz-Muñoz is with Universidad del Atlántico. Mechanical Engineering Program. Puerto Colombia, Colombia (e-mail: nelsonmunoz@ mail.uniatlantico.edu.co).

H. N. Julio-Gonzalez is with Universidad del Atlántico. Mechanical Engineering Program. Puerto Colombia, Colombia (e-mail: mail.uniatlantico.edu.co).

C. Pedraza-Yepes is with Universidad del Atlántico. Mechanical Engineering Program. CONFORMAT Research Group. Puerto Colombia, Colombia (e-mail: cristianpedraza@mail.uniatlantico.edu.co).
Barranquilla, con las condiciones ambientales locales. Las pruebas experimentales del prototipo permitieron validar el diseño propuesto en este trabajo.

Palabras claves - Análisis óptico, Baja entalpía, Colector solar lineal, Fresnel.

\section{INTRODUCTION}

INCE the late eighteenth century, the world accelerated its Neconomic development due the emergence of the steam engine. Therefore, an inventiveness of great impact that influenced a great industrial revolution in Western Europe and America [1]. This invention was preceded many other technologies in order to be used for energy applications, such as the development of thermal engines that used petroleum products, e.g.: kerosene, LPG, gasoline, etc. However, nowadays, these products are discredited due to the great damage that they cause to the environment, specially, by the emissions of $\mathrm{CO} 2$, a common product of combustion in these types of engines, and the great cause of damage to the Ozone coat [2]. Thus, in the international science community, different efforts have been made to stop the use of these kind of fuels. Efforts for the use of a new technological changes in thermal and energy applications have been increased. Developing new alternative energy sources is the current challenge. Hence, today new renewable technologies have been developed, that use thermal energy from renewable sources such as solar energy that have potential uses for the energy generation and HVAC applications. In addition, effective technologies have been developed to recover the waste heat in industrial processes for energy generation purposes [3], which have received great acceptance in the industrial sector. In fact, this given the

O. Higuera-Cobos is with Universidad del Atlántico. Mechanical Engineering Program. CONFORMAT Research Group. Puerto Colombia, Colombia (e-mail: oscarhiguera@mail.uniatlantico.edu.co).

J. D. Hernández-Vásquez is with Universidad Antonio Nariño. Faculty of Mechanical, Electronic and Biomedical Engineering (FIMEB). Mechanical Engineering Program. GIFOURIER Research Group. Puerto Colombia, Colombia (e-mail: johernandez79@uan.edu.co). 
representative economic benefits and the effectiveness of the production processes, especially in those that work extensively with chemical reactions, washing, drying and sterilization of products, with furnaces, compressors, chillers and thermal motors, etc. [4].

In particular, the thermal energy that can be generated from a solar installation, can be used from conventional turbines in large solar plants and also in smaller scale as heat sources of low enthalpy with ORC turbines or the use of sunroofs or engines Stirling. Also, in the air conditioning applications can also be used by means of Chiller or absorption heat pumps, or heating / cooling systems with PCM materials. All these applications are possible with the use of solar heat as a source of thermal energy.

\section{DESIGN METHODOLOGY}

The optical development employed in this work, follows a methodical approach by J. Monreal [5], which has as its essence the combination of the reported works of S.S Mathur, T.C. Kandpal and BS Neggi (1990 - 1991) [6]. These literature explain topics on concentration distribution and describes of optical parameters such as width, spacing and mirrors angle. Moreover, these concepts are discussed in a series of equations, which was proposed in 1999 by PLSingh, S. Ganesan and G.yadava, [7]. These authors came to provide other mathematical approaches to understand the effect of the geometrical parameters of the collector with the final performance, i.e.: the efficiency of the concentrator decreases with the increase in the number of the mirrors, the optimum widths of the reflectors, etc. In addition, this methodical combines other articles of solar optics such as those of WR McClntire of 1979 [8] for the sizing of the receiver cusp.

In this methodology, some hypothesis are considered. Such as: all the reflective elements move while the structure of the collector remains fixed, taking also the following considerations and,

- All reflective surfaces are specular and free of deformations.

- Each reflector is pivoted in the center of its longitudinal axis.

- The movement axes of each reflector are in the same plane.

- The reflective elements do not shade each other during the operating period from 9:00h to 15:00 p.m. (solar time).

- The solar acceptance angle is independent of atmospheric conditions.

- The solar rays gives an angle $\xi=32^{\prime}=4.65 \mathrm{mrad}$ and are independent of atmospheric conditions.

- The sun passes through the zenith.

- All the elements of the mirror have the same width and the same length.

- $\quad$ The system uses a CPC cusp as secondary concentrator.

The Fig. 1 shows how the sun's rays affect the solar concentrator as shown in the Fig. 1.

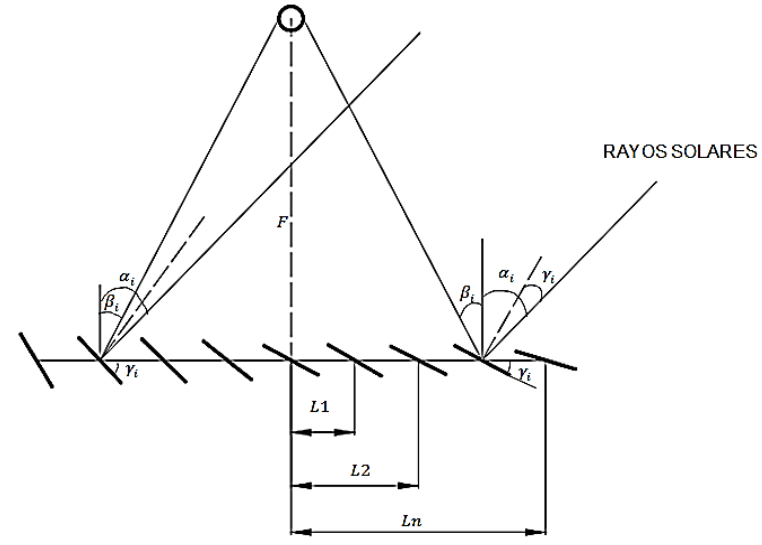

Fig. 1. Incident rays to the solar concentrator, $f$ is the height of the horizontal receiver flat with respect to the plane where the mirrors are located, $W$ is the width of each mirror, $\gamma$ the angles of the mirror inclination.

The angle of each reflective element was calculated from the solar incidence angle $\alpha$ and its location with respect to the central line of the collector, the initial operating conditions at 9:00h are considered: $\alpha_{0}=45^{\circ}, \beta=0$ y $\mathrm{L}_{0}=0$.

On the other hand, considering the spacing of the reflectors in the model, it was noted that the reflective mirrors on the left side was showing greater shading problems, since those on the right side are closer to the horizontal, while those on the left side are more horizontal. Closer to the vertical causing longer or distended shadows on the plane of the collector, with this condition as a reference, using mathematical tools, the spacing between the mirrors was found. In order to avoid shading between the mirrors with respect to the inclination and angle of incidence of the Sun's rays, shown in (1) and (2), which can only be solved with numerical methods, whose iterative equations varies from 0 to $n(0<\mathrm{i}<\mathrm{n})$, where $\mathrm{n}$ is the number of reflector elements that are only to the left of the central reference element of the collector.

$$
\begin{array}{r}
\gamma_{i}=\frac{1}{2} \tan ^{-1}\left[\left(\frac{W}{2 f}\left(\frac{\operatorname{sen} \gamma_{i-1}+\operatorname{sen} \gamma_{i}}{\tan (90-\alpha+\epsilon)}+\cos \gamma_{i-1}+\cos \gamma_{i}\right)\right.\right. \\
\left.\left.+\frac{L_{i-1}}{f}\right)\right]+\frac{\alpha}{2}(1) \\
L_{i}=L_{i-1}+\frac{W}{2}\left(\frac{\operatorname{sen} \gamma_{i-1}+\operatorname{sen} \gamma_{i}}{\tan (90-\alpha+\epsilon)}+\cos \gamma_{i-1}+\cos \gamma_{i}\right)
\end{array}
$$

Subsequently, to find the equations of the right side, the same trigonometric relationships were used. Additionally, considering the symmetry of the collector, so the same amount and the same spacing between the reflective elements of the left side must be had, thus it is necessary, $\mathrm{L}_{\mathrm{i}}=\mathrm{L}_{\mathrm{d}}$. Once the mirrors spacing on the right side has been defined, the determination of the angles of the reflective elements is calculated using the following trigonometric relationship :

$$
\gamma_{d}=\frac{\alpha-\tan ^{-1}\left(\frac{L_{d}}{f}\right)}{2}
$$


Where the subscript $d$ varies from 0 to $n$, that is $(0 \leq d \leq n)$ and $\mathrm{n}$ is the number of elements on the right side.

With the objective to define the width of a flat receiver, the last element on the left side of the collector was considered, because this element has the maximum inclination at the initial operating period, and it will give the widest image on the plane of the receiver as shown in the Fig. 2.

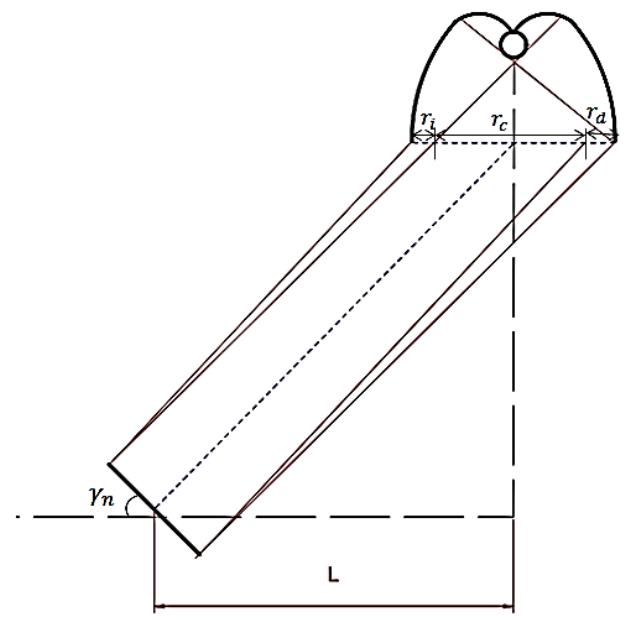

Fig. 2. Final mirror showing the maximum width of the receiver's cusp.

The width value of the receiver's cusp is calculated by:

$$
R_{p l}=r_{i}+r_{c}+r_{d}
$$

Additionally,

$$
\begin{gathered}
r_{d}=\left(f+\frac{W}{2} \operatorname{sen} \gamma_{n}\right)\left(\operatorname { t a n } \left(\tan ^{-1}\left(\frac{L n}{f}+\epsilon\right)-\tan \left(\tan ^{-1}\left(\frac{L n}{f}\right)\right)(5)\right.\right. \\
r_{c}=W \cos \gamma_{n}+W \operatorname{sen} \gamma_{n} \tan \left(\tan ^{-1}\left(\frac{L n}{f}\right)\right)(6) \\
r_{i}=\left(f-\frac{W}{2} \operatorname{sen}_{n}\right)\left(\tan \left(\tan ^{-1}\left(\frac{L n}{f}\right)\right)-\tan \left(\tan ^{-1}\left(\frac{L n}{f}-\epsilon\right)\right)\right)
\end{gathered}
$$

As shown in Fig. 3, the receiver that was used, has a cylindrical geometry with a radius $\mathrm{R}$. On the other hand, the geometric profile of the receiver's cusp shows an irregular geometry that is described with two given mathematical segments in (8) and (9) [50]. Which are joined at the point $\mathrm{P}$ related in addition to a critical angle as shown in Fig. 3.

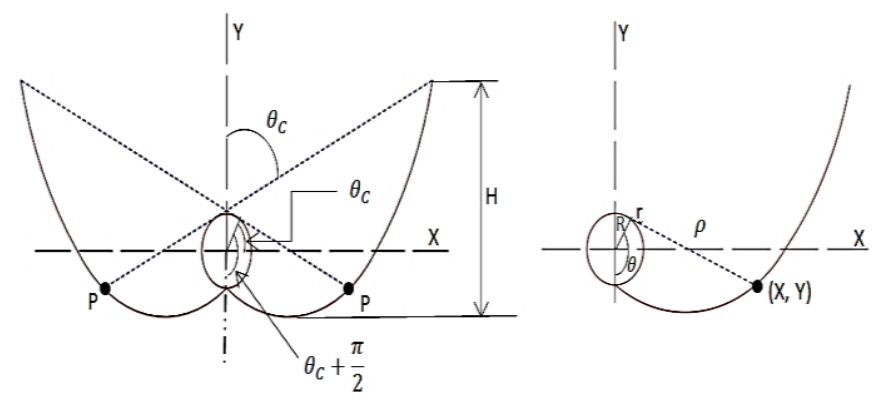

Fig. 3. Secondary non-image Cusp concentrator geometry.

$$
\begin{gathered}
\rho=R \theta,|\theta| \leq \theta_{C}+\frac{\pi}{2} \\
\rho=R\left(\frac{\theta+\theta_{C}+\frac{\pi}{2}-\cos \left(\theta-\theta_{C}\right)}{1+\operatorname{sen}\left(\theta-\theta_{C}\right)}\right), \theta_{C}+\frac{\pi}{2} \leq \theta \leq \frac{3 \pi}{2}-\theta_{C}
\end{gathered}
$$

Equation 8 reproduces the first segment in the lower part up to the point $\mathrm{P}$ which is the involute of the receiver of circular section, while (9) reproduces the second segment from point $\mathrm{P}$ to the upper part of the curve allows the capture and reflection of the rays that strike with an angle smaller than the acceptance angle. Both equations for $\rho$ are equivalent for point $P$ in Fig. 3, where $\theta=\theta_{c}+\frac{\pi}{2}$. The curve is generated by increasing the value of the angle, calculating and then to calculate the $\mathrm{X}$ and Y coordinates:

$$
\begin{gathered}
X=R \operatorname{sen} \theta-\rho \cos \theta(10) \\
Y=-R \cos \theta-\rho \operatorname{sen} \theta(11)
\end{gathered}
$$

Given the value of the last mirror, which will give the widest image on the plane of the receiver, it is matched with the coordinate in $\mathrm{X}$, at its extreme value of the Cusp-CPC nonimage concentrator curve, thus:

$$
X_{e}=r_{i}+\frac{r_{c}}{2}
$$

So, the angular endpoint value of the cusp $\left(\frac{3 \pi}{2}-\theta_{C}\right)$ is replaced in (9), (10) and (11), and from these we get to the following system of equations, which represent the final values of the cusp:

$$
\begin{gathered}
\frac{r_{c}}{2}+r_{i}=R \operatorname{sen}\left(\frac{3 \pi}{2}-\theta_{C}\right)-\rho_{e} \cos \left(\frac{3 \pi}{2}-\theta_{C}\right) \\
Y_{e}=-R \cos \left(\frac{3 \pi}{2}-\theta_{C}\right)-\rho_{e} \operatorname{sen}\left(\frac{3 \pi}{2}-\theta_{C}\right) \\
\rho_{e}=R\left(\frac{2 \pi-\cos \left(\frac{3 \pi}{2}-2 \theta_{C}\right)}{1+\operatorname{sen}\left(\frac{3 \pi}{2}-2 \theta_{C}\right)}\right)
\end{gathered}
$$

Based on all the equations shown, the final sizing of the system and the cusp is built. Tables I and II summarize the results.

TABLE 1. FINAL ARRANGEMENT OF THE SOLAR COLLECTOR MIRRORS

\begin{tabular}{cccc}
\hline \multirow{2}{*}{ Mirrors } & \multicolumn{2}{c}{ Inclination $\boldsymbol{\gamma}_{\boldsymbol{i}}$} & \multirow{2}{*}{ Spacings $\boldsymbol{L}_{\boldsymbol{i}}(\mathrm{cm})$} \\
\hline 1 & 0.131 & 7.485 & -115.610 \\
2 & 0.164 & 9.370 & -98.668 \\
3 & 0.199 & 11.375 & -81.822 \\
4 & 0.235 & 13.485 & -65.098 \\
5 & 0.274 & 15.681 & -48.525 \\
6 & 0.313 & 17.936 & -32.132 \\
7 & 0.353 & 20.220 & -15.949 \\
8 & 0393 & 22,500 & 0.0000 \\
9 & 0.432 & 24.765 & 15,949 \\
10 & 0.472 & 27.049 & 32.132 \\
11 & 0.511 & 29.306 & 48.525 \\
12 & 0.550 & 31.502 & 65.098 \\
13 & 0587 & 33.613 & 81.822 \\
14 & 0.622 & 35.619 & 98.668 \\
15 & 0.655 & 37.505 & 115.610 \\
\hline \hline
\end{tabular}


TABLE II. FINAL SIZING OF THE SOLAR COLLECTOR CUSP

\begin{tabular}{cc}
\hline $\boldsymbol{\theta}_{\boldsymbol{c}}$ & $0,6546 \mathrm{rad}$ \\
$\boldsymbol{\rho}_{\boldsymbol{e}}$ & $176,99 \mathrm{~mm}$ \\
$\mathbf{R}$ & $25,4 \mathrm{~mm}$ \\
$\boldsymbol{X}_{\boldsymbol{e}}$ & $77,84 \mathrm{~mm}$ \\
$\boldsymbol{Y}_{\boldsymbol{e}}$ & $159,44 \mathrm{~mm}$ \\
\hline \hline
\end{tabular}

On the other hand, the thermal efficiency of the collector can be calculated with the following expression [9]:

$$
\eta=F * \alpha_{s}-F * U_{L} \frac{T_{f}-T \infty}{G C_{1}}
$$

Where the value $F * \alpha_{s}$ is defined as the optical performance of the collector, and the value $F * U_{L}$ is defined as the collector loss factor. Additionally, $\mathrm{F}$ is the heat removal factor, which is obtained from the following equations

$$
F=\frac{m C_{p}}{A_{a b s} U_{L}}\left[1-\exp \left(-\frac{U_{L} F^{\prime \prime} A_{-} a b s}{m C_{p}}\right)\right]
$$

Additionally [10],

$$
\begin{gathered}
F^{\prime \prime}=\frac{U_{0}}{U_{L}}(18) \\
U_{O}=\frac{1}{U_{L}}+\frac{D_{\text {exterior }}}{h_{\text {aire }} D_{\text {interior }}}+\frac{D_{\text {exterior }} \operatorname{Ln}\left(\frac{D_{\text {exterior }}}{D_{\text {interior }}}\right)}{2 * k} \\
U_{L}=\frac{1}{R_{\text {total }} A_{\text {abs }}}(20)
\end{gathered}
$$

\section{MATHERIAL AND METHODS}

The structure of the collector was based on a construction with angles profiles of AISI A36 1/8 1 "-1 1/2" steel, welded most at the base, aligning and giving more resistance against the effects of wind. Additionally, so that the structure would be more resistant to the adverse effects of the weather. For the assembly, struts were used to guarantee the fidelity of the measurements and the correct disposition of each of the angles profile welded in the structure. In general, the structure, although most of it has welded joints, it is built of four parts joined with screws. The support base, the sides and the two front-rear structure, in the latter is where the weight of the cusp rests, two Carbon steel angles profiles align both structures in parallel, in the same way, in the lower part with the base, they are joined.

On the other hand, the mirrors were supported by the same structure. These were mounted on a stabilizer frame of flat base steel and a tube in each one, said tubes are arranged longitudinally through the mirrors to avoid buckling between the transverse steel beams, and they are joined by screws with a system of bearings for $1 / 2$ "shafts, so the rigidity and the suitability of the reflectors are guaranteed. Taking into account the dimensions calculated in the a priori methodologies, and which subsequently proved to be successful, since the sunlight reflected by the mirrors always found the focus of the surface of the cusp without any inconvenience. The final construction is shown in the Fig. 4.

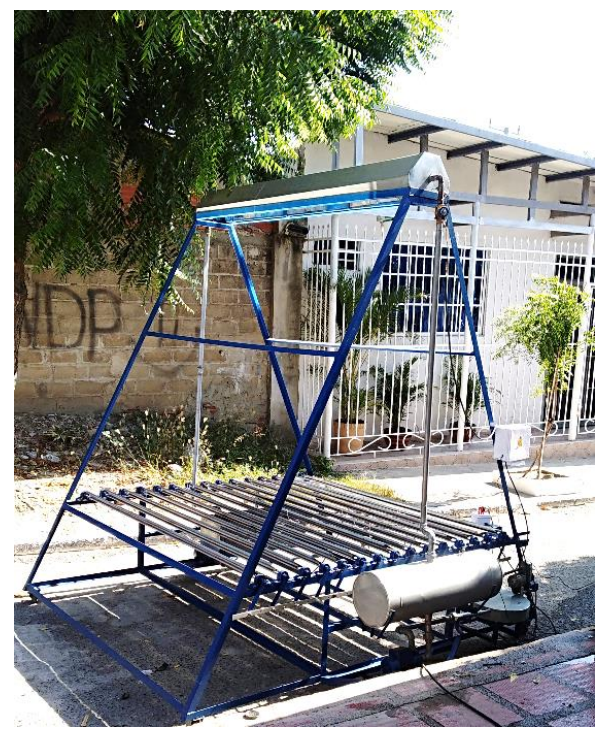

Fig. 4. Collector in the final version

It is important to highlight that the non-truncated composite concentrator was made by galvanized steel with an insulating coating of glass wool insulating in the intermediate space between the reflector and the housing, in order to minimize the radiation and convection losses. After that, in operation had the total capacity to reflect to the receiver all the incident radiation in the reflector, within the acceptance angle, as it was designed a priori. The receiver, on the other hand, was made from a 0.026 $\mathrm{m}$ diameter absorber tube, made of copper, and a wall thickness of $0.004 \mathrm{~m}$, which makes it suitable for heat transfer by the high thermal conductivity. This is mounted at an elevation of 2 meters above the horizontal surface and parallel to the plane of the mirrors, housed next to the secondary reflector. In the middle of it the thermal oil is circulated, fluid to which it will rise in temperature. Finally, for the development of the tracking mechanism an articulated parallelogram mechanism operated with a linear motor of $80 \mathrm{~W}$ was used.

\section{RESULTS AND DISCUSSION}

In order to perform the performance tests of the system, and so determine the behavior of the built system, a series of three tests was carried out, which allowed to obtain a data set obtained from direct graphical observation and from the instrumentation of the system. The first test is a descriptive type; once the equipment was built in the field, the geometrical arrangement of the mirrors was checked, and it was corroborated by success, since the mirrors reflected the sunlight to the desired position with the measurements and inclinations were calculated work, with the hypothesis that the collector was located frontally to the sun to the defined orientation of the collector to NorthSouth, with apparent tracking of the Sun in an East-West direction, so that the mirrors reflect sunlight towards the top of the shape to which it was designed. 
The second test, on the other hand, and being measurable, corresponds to the obtaining of the heating curves of the oil and the curve of instantaneous efficiency of the collector, then these obtained data are fundamental to define the performance of the equipment at its operating conditions. The results are show in the Table III.

TABLE III. OIL THERMAL STORAGE PERFORMANCE

\begin{tabular}{ccc}
\hline \hline $\begin{array}{c}\text { Experimentation } \\
\text { Day }\end{array}$ & Oil stored $(L)$ & $\begin{array}{c}\text { Temperature } \\
\text { max/min } \\
\text { achieved }\left({ }^{\circ} \text { C }\right)\end{array}$ \\
\hline $\mathbf{1 5 - 0 4 - 2 0 1 8}$ & 21 & $140 / 108$ \\
$\mathbf{1 6}-\mathbf{0 4 - 2 0 1 8}$ & 25 & $135 / 110$ \\
$\mathbf{1 7 - 0 4 - 2 0 1 8}$ & 23 & $130 / 100$ \\
\hline \hline
\end{tabular}

The ambient and concentrator temperatures measured on April 15, 2018 at 11:00h (time at which the highest solar incidence occurred during the three days of testing, Table 3 ) with the eastwest monitoring system and guidance North-South is described in Fig. 5.

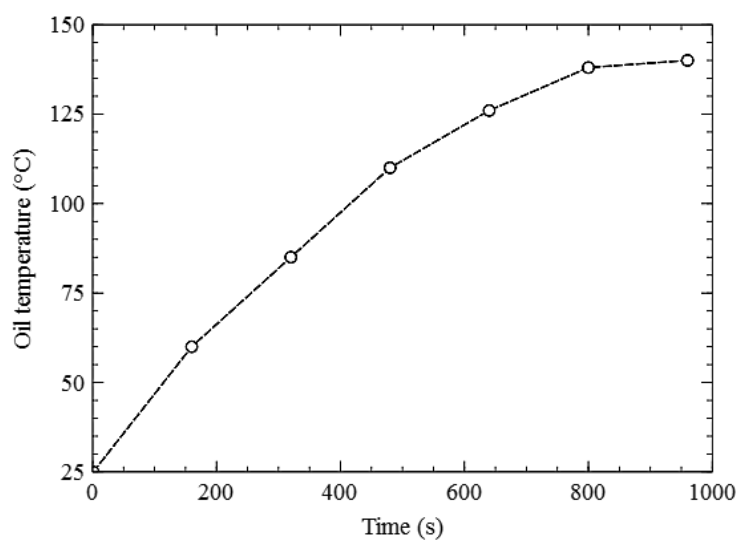

Fig. 5. Experimental heating performance of the collector (11:00 am, April 15, 2018)

The experimental results show that the increase in the temperature of the working fluid do not occur with a linear behavior, but increases incrementally until reaching a stagnation temperature, due to the increase of the thermal losses, which increase in parallel with the increase of the temperature. This behavior is also reflected in the results of a Fresnel linear concentrator of 10.6 Soles located in Puno, Peru, which showed average temperatures of the absorber tube is $219.8^{\circ} \mathrm{C}$ with local solar radiation of $701.5 \mathrm{~W} / \mathrm{m}^{2}$ [11], but with an increase gradual performance similar to the results of Fig. 5, in the same way another Fresnel linear concentrator reaches 180 ${ }^{\circ} \mathrm{C}[12]$ with the same heating profile.

On the other hand, in the third test, the authors proceeded with the characterization of thermal efficiency. In this case, it was used (17) - (21) and the values provided by the Universidad del Atlántico database. Then, during the experimentation stages and the values of the loss coefficients and the removal factor of the receiver, which are achieved by means of the proposed arrangement of Fig. 7 corresponding to the test of the characterization of the collector loss coefficient, in the absence of sunlight, using a differential temperature thermostat that heated the water to $90{ }^{\circ} \mathrm{C}$ and that additional guaranteed the operation of the pump until the temperature was reached and then later, proceed to get the loss coefficient of the receiver. Fig. 6 describes this situation.

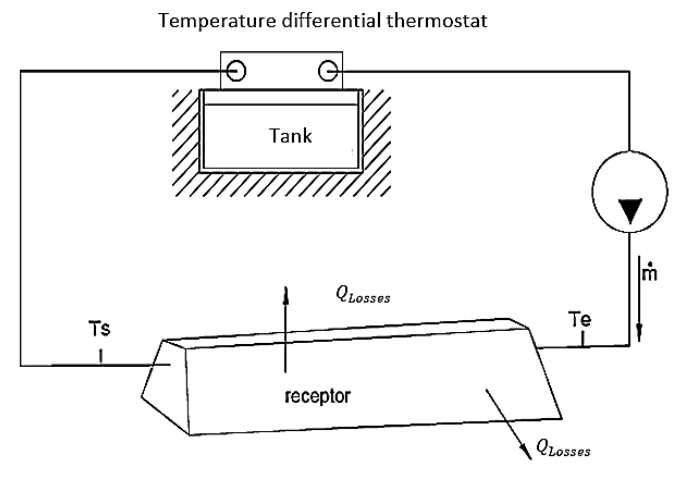

Fig. 6. Test bench for the calculation of the receiver loss coefficient

Fig. 7 illustrates the results of the instantaneous efficiency.

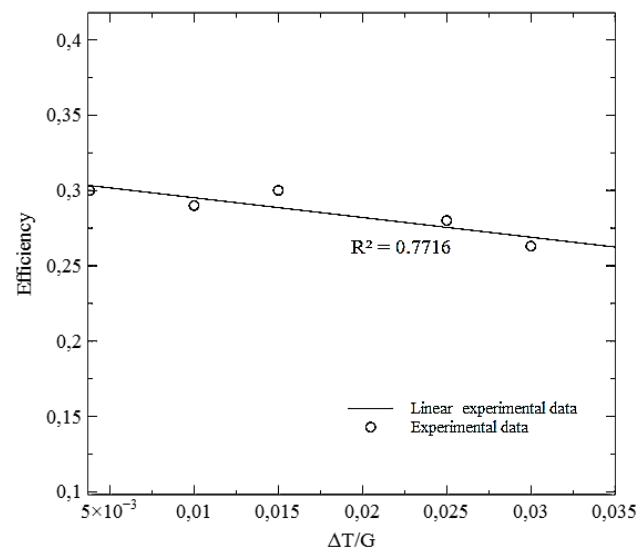

Fig. 7. Experimental efficiency of the collector

The consolidated results in last experimental test, that it has done in parallel with the previous tests (Fig. 5), the collector shows a maximum efficiency of $30 \%$ quite acceptable value, since most of these types of concentrators shows efficiency surround from 20 to $60 \%$. In the case of a Fresnel concentrator for steam heating in Mexico, it reports an efficiency of $30 \%$ to $40 \%$ [13], additionally for other linear concentrator used for desalination application showed efficiencies about 38\% [14], very similar to the presented work.

\section{CONCLUSIONS}

In this work, the design, construction and evaluation of a Fresnel linear concentrator for oil heating was carried out. The alignment of the mirrors was made from a geometric methodology which also allowed to define the dimensions of the absorber, the width and depth of the cusp and the rest of the significant measurements of the solar collection process (height of focus $f=0.2 \mathrm{~m}$, width of mirrors $\mathrm{w}=0.12 \mathrm{~m}$, and number of mirrors $=15$ ). Subsequently, this study allows us to develop the conclusive conceptual design and construction plans, which subsequently allowed the quotation and construction of all the mechanical elements of the collector. 
Once the physical construction of the collector has been developed and also the relevant instrumentation for the control of the valves and auxiliary systems, a series of experimental tests were carried out, from which it was possible to obtain conclusions about the operation and performance of the collection system solar. On the other hand, the working oil can reach maximum temperatures of $140{ }^{\circ} \mathrm{C}$ with an experimental thermal efficiency of $30 \%$, in accordance with that established in the literature for medium temperature concentrators.

Final recommendations on the current design are given, considering changes in the receiver, since the use of some glass envelope is recommended, and as far as possible a vacuum envelope, to improve the heating insulation in the receiver, also improving the current insulation by contact of the secondary concentrator. On the other hand, it should be noted that the oil once heated falls by gravity to the tank, provided that the collector is slightly inclined. So, in general this process can be realized within 3 to 4 minutes for each cycle; this can be improved with the use of an auxiliary pump, and would make the collector need no inclination. Finally, the solar collector presented and its capacity to heat thermal oil has potential use in other applications such as absorption chillers systems, where thermal deposits are directly used to feed the cooler and additionally, in chemical processes, where heat is needed for chemical reaction process, this type of collector could have a meaningful use.

\section{ACKNOWLEDGMENT}

The authors gratefully acknowledge the support of The Universidad del Atlántico Engineering College for the realization of this project.

\section{REFERENCES}

[1] Biblioteca Ceibal, "James Watt y la máquina a vapor," p. 3.

[2] W. Soon, S. Baliunas, A. Robinson, and Z. Robinson, "Environmental effects of increased atmospheric carbon dioxide," Clim. Res., vol. 13, pp. 149-164, 1999. DOI:10.3354/cr013149

[3] B. Inc, "Waste Heat Recovery: Technology Opportunities in the US Industry" Waste Heat Recover. Technol. Oppor. US Ind., pp. 1-112, 2008. DOI: 10.2172/1218716

[4] M. Nored, M. Wilcox, and R. Mckee, "Waste Heat Recovery Technology Overview [DRAFT] QTR,” U.S. Dep. Energy, p. 27, 2015.

[5] Jorge A. Monreal Cruz, "Diseño de un concentrador solar lineal tipo fresnel de baja entalpía para calor de procesos", 2009.

[6] S. S. MATHUR, T. C. KANDPAL and B. S. NEGI, "Optical design and concentration characteristics of linear Fresnel reflector solar concentrators - - II. mirror elements of equal width" vol. 31, no. 3, pp. 221-232, 1991. DOI: 10.1016/01968904(91)90076-U

[7] P. L. Singh, S. Ganesan, and G. C. Yàdav, "Technical note: Performance study of a linear Fresnel concentrating solar device" Renew. Energy, vol. 18, no. 3, pp. 409-416, 1999. DOI: $10.1016 / \mathrm{S} 0960-1481(98) 00805-2$

[8] W. R. McIntire, "Truncation of nonimaging cusp concentrators" Sol. Energy, vol. 23, no. 4, pp. 351-355, 1979. DOI:10.1016/0038-092X(79)90130-0

[9] S. Polvongsri and F. O. F. Engineering, "Ashrae standard 932003 methods of testing to determine flat-plate solar collectors by" pp. 5-9, 2013.

[10] Soteris A. Kalogirou, Solar Energy Engineering. Processes and Systems, 2009

[11] J. C. Chacolla, “'Diseño, Construcción y Evaluación de un Reflector Solar Fresnel de Concentración de Foco Lineal para Generar Vapor de Agua"

[12] M. Berger, "zur Solaren Kälteerzeugung Abschlussbericht über ein Entwicklungsprojekt,” 2007.

[13] C. Cifuentes Álvaro, "Evaluación de un concentrador solar lineal tipo fresnel de baja entalpía" ,Mexico, 2003

[14] E. Saettone, "Utilización de un concentrador solar tipo Fresnel lineal para desalinación.

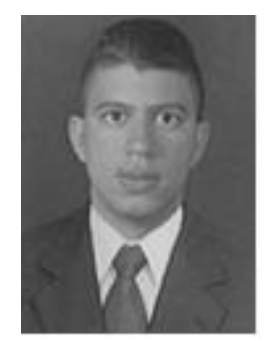

Nelson de la Hoz Muñoz. Mechanical Engineer from Universidad del Atlántico, with experience in the use of assisted design engineering programs (AutoCAD, Solidworks, Rhinoceros, Inventor fusion and MasterCAM), focused on metal fabrication. Researcher in thermal engineering, participating in projects related to the solar panel system for basic education schools. He has international experience in Brazil, participating in projects related to the production of biodiesel in CIANTEC plants and laboratories.

ORCID: http://orcid.org/0000-0001-8147-1936

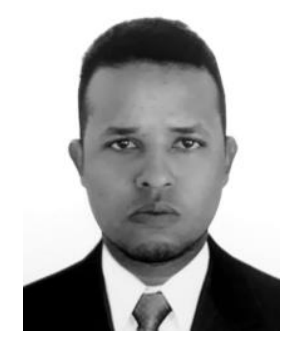

Habib Naizir Julio Gonzalez. Mechanical Engineer from the Universidad del Atlántico, with experience in the area of port logistics, performing the role of Operations Supervisor, especially in the attention of tankers and distribution through tanker trucks and others. He has extensive knowledge in the design of mechanical systems, as well as their respective maintenance. In the same way in topics related to the thermal area, as well as in control and automation systems.

ORCID: http://orcid.org/0000-0002-2765-1343 


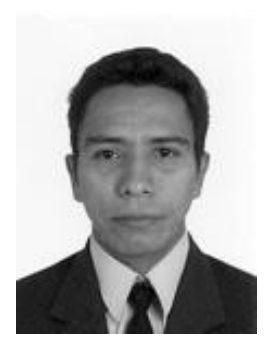

Cristian Antonio Pedraza Yepes. He was born in Barranquilla, Atlántico, Colombia in 1975. He received his B.S degree in Mechanical Engineering from the Universidad del Atlántico, Barranquilla, Colombia in 2001. He was graduated as Master in Mechanical Engineering from Universidad del Norte, Barranquilla, Colombia in 2011. He currently work as Associate Professor and member of the CONFORMAT Research Group of the Mechanical Engineering Program of the Faculty of Engineering of the Universidad del Atlántico, Colombia. Areas of research interest include Mechanical Design, Manufacturing Processes, Materials Characterization, and Alternative Energy Generation.

ORCID: http://orcid.org/0000-0002-5951-7835

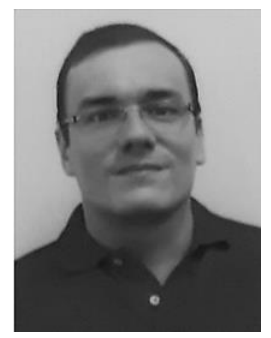

Oscar Fabian Higuera Cobos. He was born in Bucaramanga, Santander, Colombia in 1976. He received the B.S. degree as Metallurgical Engineer in 2000, M.Sc. in Metallurgical Engineering in 2004 from Universidad Industrial de Santander and Ph.D. in Materials Science and Engineering from Universidad Politécnica de Cataluña, Spain in 2013. Since 2001 and during his master's degree studies (2004), he worked as a professor at the Universidad Industrial de Santander. Subsequently, he worked as a plant professor at the Universidad Tecnológica de Pereira in the period 2005-2015. Currently, he is an associate professor and director of the CONFORMAT Research Group of the Mechanical Engineering Program of the Faculty of Engineering of the Universidad del Atlántico. He is the author of 2 books related to the areas of materials and tribology, as well as different articles related to Metallurgical Engineering and Material Engineering Science. Dr. Higuera's main research areas are related to severe plastic deformation, electrochemistry and environment, physical metallurgy, heat treatments and advanced materials.

ORCID: http://orcid.org/0000-0002-4836-5215

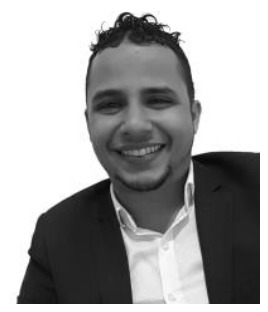

José Daniel Hernández Vásquez. Doctor in Mechanical Engineering, formed by the Pontifical Catholic University of Rio de Janeiro (PUC-Rio, 2018). Master in Metrology (PUC-Rio, 2014). Mechanical Engineer (Universidad del Atlántico, 2011). During his postgraduate training he was awarded a scholarship by institutions of the Brazilian Government for the development of science and technology: CAPES, FAPERJ and CNPq. He has teaching experience at undergraduate and graduate level, ministering disciplines at the Department of Electrical Engineering and the Graduate Program in Metrology of the PUC-Rio and Faculty of Engineering of the Universidad del Atlántico.

$\mathrm{He}$ has experience as a researcher and consultant of the Brazilian industry, acting in projects financed by the Brazilian Regulatory Body of the Electric System (Aneel) and the
National Agency of Petroleum, Natural Gas and Biofuels (ANP / PETROBRAS). Focused projects, specifically to: (i) evaluate the measurement uncertainty of heat transfer systems and (ii) develop a methodology for calibration and metrological evaluation of liquid and natural gas ultrasonic meters.

He has experience in the technical and administrative management of Metrology Laboratories. He is recognized by the Red Colombiana de Metrología (RCM, Sub-Network: Academia, Industry), as an expert in Metrology for the Colombian market. Currently, he works as a Full Time Professor with Exclusive Dedication in the Faculty of Mechanical, Electronic and Biomedical Engineering (FIMEB), Mechanical Engineering Program of the Universidad Antonio Nariño.

ORCID: http://orcid.org/0000-0002-0028-2912 